\section{COVID-19: la pandemia del olvido científico}

Ya han pasado doce meses (o una eternidad en tiempos del COVID-19) desde que en Wuhan, China, se reportaban los primeros casos de una neumonía atípica grave de etiología no identificada. Un nuevo betacoronavirus de la familia del SARS y del MERS era el agente etiológico de esos casos. Se lo definió inicialmente como 2019-nCoV y luego como SARS-CoV-2 para emparentarlo con su predecesor. A la enfermedad que producía, COVID-19.

Los primeros reportes de China daban cuenta de la verdadera dimensión del problema. Un R0 mayor a 2 nos obligaba a pensar un crecimiento exponencial y no lineal. La tasa de letalidad fue informada cercana al $3 \%$ y la misma aumentaba a medida que aumentaba la edad del paciente.

La discusión inicialmente pasaba por si la letalidad era alta o baja, mayor o menor a la de la gripe estacional, la neumonía aguda de la comunidad o el dengue. Pero el verdadero problema no estaba en el RO ni en la letalidad, sino en la combinación de ambos elementos. Y tal vez ayudado por el sesgo del crecimiento exponencial (dificultad para comprender cuán rápido puede ser este crecimiento) y la lejanía de China, el virus llegó como un tsunami al norte de Italia y luego al resto del mal llamado viejo continente. Y casi como la crónica de un final anunciado, en los primeros días de marzo de 2020 se reportó el primer caso de COVID-19 en Argentina. A partir de ese momento es historia conocida. Términos como "distanciamiento social", "aplanar la curva" y "cuarentena" pasaron a formar parte de nuestra cotidianidad.

El furor curandis por hallar un tratamiento efectivo causó que el mundo científico entrara casi sin darse cuenta en una especie de insomnio y olvido colectivo. El realismo mágico primó por sobre el método científico. Moléculas sin más sustento científico que alguna efectividad in vitro pasaron a ser las falacias irrefutables de ese momento. Fue así como, al comienzo de la pandemia, hidroxicloquina (monoterapia o en combinación con azitromicina), lopinavir/ritonavir y tocilizumab fueron los pilares del tratamiento de COVID-19. Más recientemente, el uso indiscriminado del plasma de convalecientes, ivermectina e ibuprofeno inhalado. Capítulo aparte merece la promoción cuasi criminal hasta en TV del uso del dióxido de cloro.

La difusión de preprints (versiones de manuscritos antes de la revisión por pares) era más rápida que la del propio virus y marcaba el rumbo científico. Llamativamente o no, muchos de esos preprints nunca fueron publicados en ninguna revista científica con revisión de pares.

A tal nivel de vorágine se llegó, que varios artículos científcos publicados tuvieron que ser retractados. Tal vez los casos más paradigmáticos fueron los publicados en dos de las revistas médicas más prestigiosas del mundo, The Lancet y The New England Journal of Medicine. Ambas se vieron obligadas a eliminar estos artículos ya que se basaban en datos cuestionables y no compartidos con los coautores y editores involucrados.

Es importante no olvidar que el conocimiento médico se construye esencialmente con el método científico, que se sustenta en la experimentación y verificación. Y fue así como los primeros resultados de ensayos clínicos bien diseñados emergieron como un verdadero antídoto para la pandemia de la (des) infodemia científica.

Estudios como el RECOVERY y el SOLIDARITY reportaron que los estandartes hasta ese momento del tratamiento de COVID-19 tenían nula efectividad clínica. Y el jugador menos pensado, dexametasona, reducía la mortalidad en pacientes con requerimiento de $\mathrm{O}_{2}$. Del mismo modo, dos estudios de investigación realizados en Argentina demostraron en qué pacientes tendría utilidad el plasma de convalecientes.

Hasta el momento se han publicado más de 85.000 artículos científicos sobre COVID-19. Sin embargo, tan solo 180 son ensayos clínicos randomizados y controlados (Fuente: Pubmed).

En lo que respecta a las vacunas, no hubo soluciones mágicas ni rápidas. Solo algunos intentos de utilizar la BCG que no llegaron a concretarse. El desarrollo de las diferentes vacunas se rigió por el método científico. A un año del inicio de la pandemia contamos como nunca en la historia de la medicina con vacunas aprobadas para uso de emergencia (Pfizer, Oxford-AztraZeneca, Moderna, Sputnik V [Instituto Gamaleya], Sinopharm) y otras 20 en fase 3. Sin embargo, el desarrollo de las vacunas no estuvo exento de algunas controversias. Problemas técnicos, así como de comunicación, atentaron en ocasiones contra la credibilidad de las tan anheladas vacunas. Afortunadamente, la buena ciencia siempre le gana a la mala prensa, y el mundo se encamina hacia una campaña de vacunación sin precedentes.

Como comunidad científica debemos aprender que la solución a una nueva enfermedad viene de la mano de estudios 
clínicos pragmáticos y bien diseñados. Con resultados que si bien no son inmediatos, pueden beneficiar o al menos no perjudicar (primum non nocere) a millones de personas.

Que el insomnio por querer curar no nos traiga el olvido.

"Abrió la maleta atiborrada de objetos indescifrables, y de entre ellos sacó un maletín con muchos frascos. Le dio a beber a José Arcadio Buendía una sustancia de color apacible, y la luz se hizo en su memoria. Los ojos se le humedecieron de llanto, antes de verse a sí mismo en una sala absurda donde los objetos estaban marcados, y antes de avergonzarse de las solemnes tonterías escritas en las paredes, $y$ aun antes de reconocer al recién llegado en un deslumbrante resplandor de alegría. Era Melquíades... Así Macondo celebraba el fin de la peste". Fragmento del libro Cien años de soledad, de Gabriel García Márquez.

\section{Dr. Ezequiel Córdova, editor invitado}

Médico Especialista en Enfermedades Infecciosas y Farmacología Clínica

Unidad de Infectología - Hospital Argerich (CABA)

Investigación Clínica - Fundación IDEAA (CABA)

Miembro de la Comisión Directiva SADI 